\title{
Clostridium difficile Infection Update for the Hospital-Based Physician
}

\author{
Sean W. Pawlowski
}

Published online: 6 September 2014

(C) Springer Science+Business Media New York 2014

\begin{abstract}
Clostridium difficile infection (CDI) hospitalization and mortality rates increased rapidly over the first decade of the 21 st century associated with the emergence of an "epidemic" $C$. difficile strain. Improved knowledge of this strain and its unique characteristics as well as $C$. difficile in general have heightened awareness to its virulence, recurrence risks, and transmissibility. The overuse of certain antimicrobials, which in turn disrupt the protective intestinal micro environment, may be driving CDI emergence. Newer treatments and those on the horizon have shown promise in their ability to reduce disease recurrence. Emergency and hospital-based physicians are frequently the first responders to patients with CDI. Therefore, the ability to identify an infected patient early, initiate appropriate medical and/or surgical management, and initiate preventative measures to impede spread and acquisition is imperative for the health of the entire hospital community.
\end{abstract}

Keywords Clostridium difficile . Epidemic .

Pseudomembrane $\cdot$ Antibiotic $\cdot$ Colectomy

\section{Introduction}

Clostridium difficile, a gram positive, spore forming, toxinproducing bacillus, is the most common cause of hospitalacquired diarrhea and the most commonly reported hospital-acquired pathogen [1]. It leads to illness ranging from mild diarrhea to fulminant disease, associated with significant morbidity and mortality. Not only is the incidence

S. W. Pawlowski $(\bowtie)$

Colorado Infectious Disease Associates, 950 E Harvard, Ste 140, Denver, CO 80210, USA

e-mail: swpawlowski@hotmail.com increasing within the hospital setting, but it is also more frequently diagnosed within the community in those with or without previous healthcare exposure [2-5]. The increased incidence of CDI parallels the emergence of an "epidemic strain" of $C$. difficile, which has been linked to higher rates of recurrence, morbidity, and mortality [6••, 7]. Unfortunately, the mainstays of treatment for this infection, metronidazole and vancomycin, are associated with high rates of recurrence as their broad antimicrobial activity leads to further destruction of the protective intestinal microbiota.

With its increased frequency in the hospital and presentation within the community, it is of the utmost importance for emergency and hospital-based physicians to recognize an infected patient early, begin appropriate treatment, recognize the need for isolation to help prevent spread through the hospital community, and take precautions in uninfected patients to prevent acquisition.

\section{Pathogenesis}

C. difficile was discovered in the 1930s by Hall and O'toole when it was isolated from the meconium of stool in asymptomatic newborns [8]. Thinking it at first a commensal bacterium due to its commonality within the normal flora of newborns, it was not considered a pathogen until the 1970s when it was discovered to cause antibioticassociated diarrhea [9]. It is a common colonizer, with up to $3-6 \%$ of people outside the hospital setting colonized and $15-52 \%$ within the acute care and long-term care settings, respectively [10-12]. Intestinal colonization resistance, through protective commensal bacteria and intestinal cell defense mechanisms, inhibits $C$. difficile growth, preventing the secretion of pathogenic toxins A 
A

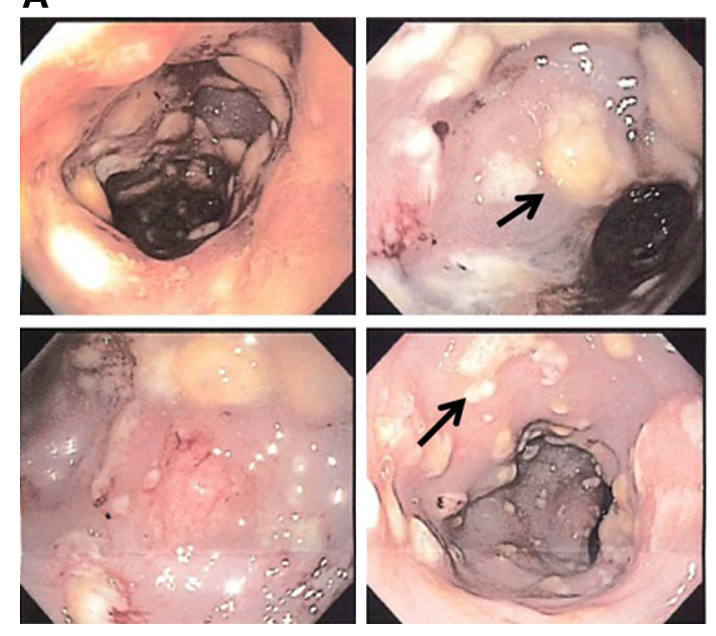

B

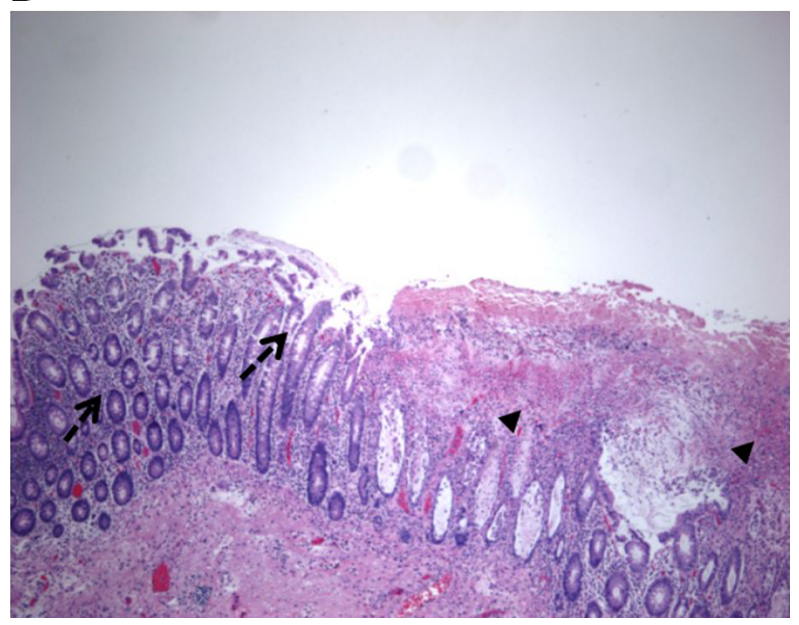

Fig. 1 a Pseudomembranes (arrows) throughout the colon in a patient with recurrent $C$. difficile infection (CDI). b A colon after subtotal colectomy for fulminant CDI. Note the necrotic cells (arrowheads) and disrupted epithelium with lymphocytic infiltration. (dashed arrows)

and $\mathrm{B}$. When colonization resistance decreases, typically through the use of broad spectrum antibiotics, but occasionally with cytotoxic agents and disorders such as Crohns or Ulcerative Colitis, colonization can then progress to $C$. difficile infection (CDI).

Toxins A and B are secreted in highest numbers during the exponential growth of the bacterium and bind to receptors on colon cells, leading to a loss of barrier function, cell death, apoptosis, and release of numerous inflammatory molecules [13]. Through its direct activity on the colon cells and the ensuing release of cytokines, an inflammatory cascade occurs, which can progress quickly in spite of adequate antimicrobial treatment. Necrosis and neutrophil accumulation accounts for the pathognomonic pseudomembranes which develop along the colon (Fig. 1). In vitro studies reveal that toxin binding, followed by the release of inflammatory cytokines occur within several minutes of exposure to the toxin, with cascade progression even when the toxin is removed after several minutes, stressing the importance of early recognition and treatment [14].

\section{Recent Epidemiologic Trends}

Small CDI outbreaks affecting long-term care facilities and hospitals were recognized throughout the 1980s and 1990s, and an overall steady increase in disease was seen from the late 1980s to 2001, but it was not until 2001 that large-scale hospital outbreaks, associated with increased morbidity and mortality were recognized (Fig. 2) [15-17]. The upward trend in hospitalizations continued, until plateauing in 2009 $[4,18]$. The upsurge in CDI has disproportionately affected older adults. Community-acquired CDI, defined as no healthcare facility exposure within 90 days of diagnosis, now accounts for as high as $10 \%$ of cases [3]. The trend parallels the emergence of an "epidemic" strain of $C$. difficile, labeled 027/NAP1/BI (by typing methods), herein referred to as the BI strain. This strain has been shown to have increased transmissibility, a 16- and 23-fold increase in toxin $\mathrm{A}$ and $\mathrm{B}$ production, respectively, enhanced sporulation, expression of a binary toxin, and increased resistance to antimicrobials and disinfectants [7, 19-23]. Recent studies have associated the BI strain with higher rates of recurrence and a near two-fold increase in severe disease, severe outcomes, and mortality as compared to other strains $[6 \bullet \bullet, 24 \bullet \bullet]$. Though present since the 1980s, it was previously never implicated as a cause of outbreaks. Genotypically identical, phenotypically, it has greater resistance to fluoroquinolones, possibly implicating increased fluoroquinolone use as a cause for its emergence [7, 17]. With the aging of our population, elevated colonization rates, an overuse of antibiotics, and the emergence of a hypervirulent strain, it is not surprising that CDI has become more problematic.

\section{Risk Factors and Prevention}

A major strategy to reduce cases is to prevent acquisition within the hospital. Once colonized, patients can develop disease when exposed to antibiotics or other medications, such as acid-reducing medications, that are able to disrupt the balance of the protective microbiota. Aging additionally predisposes patients to disease acquisition. The risk factors and prevention strategies to reduce these risks will be discussed in the sections to follow (Table 1) [17, 25, 26]. 
Fig. 2 Trends in hospitalizations (1999-2009) and mortality (1999-2004) associated with $C$. difficile infection (CDI)

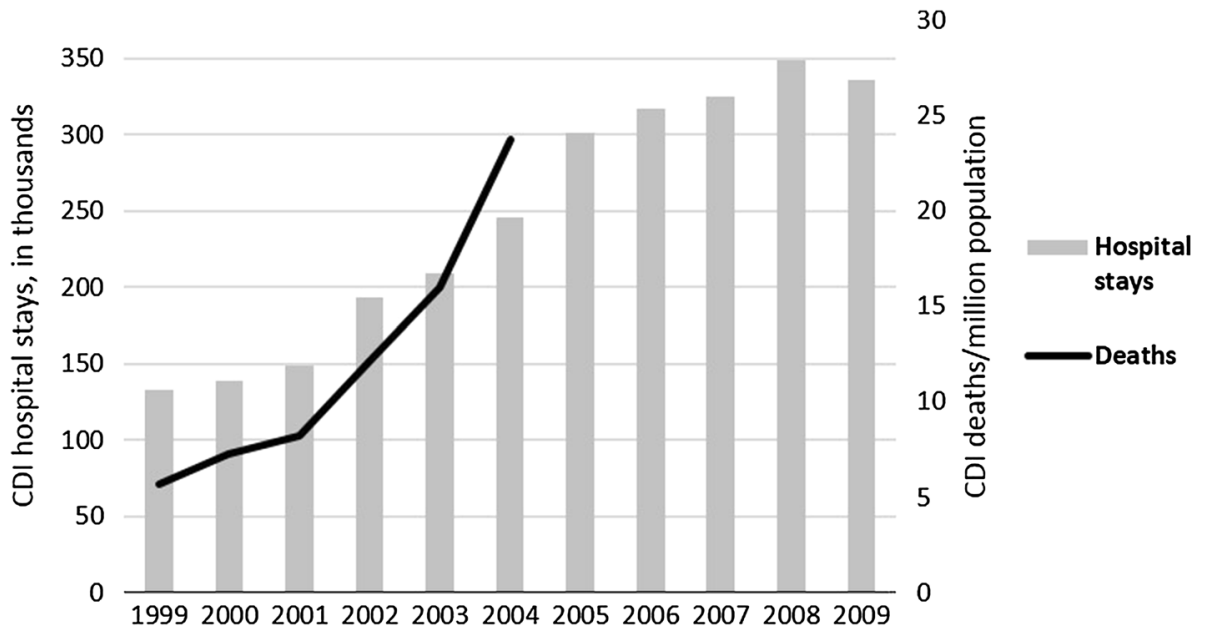

Table 1 Risk factors for acquisition of CDI and strategies to decrease risk

\begin{tabular}{|c|c|}
\hline $\begin{array}{l}\text { Risk factors for } \\
\text { acquisition of CDI }\end{array}$ & Strategies to decrease risk \\
\hline $\begin{array}{l}\text { Antimicrobial } \\
\text { exposure }\end{array}$ & $\begin{array}{l}\text { Development of an ASP or other program } \\
\text { to encourage the appropriate use of } \\
\text { antibiotics }\end{array}$ \\
\hline \multirow[t]{2}{*}{ Exposure to $C$. difficile } & $\begin{array}{l}\text { Active Infection Prevention program to } \\
\text { promote isolation of patients with CDI } \\
\text { and encourage gowning, gloving, and } \\
\text { hand hygiene }\end{array}$ \\
\hline & $\begin{array}{l}\text { Environmental cleaning with effective } \\
\text { sporicidal agents }\end{array}$ \\
\hline Advanced age & $\begin{array}{l}\text { Identification that age is a risk factor and } \\
\text { avoid antibiotics and other medications } \\
\text { associated with an increased risk of CDI }\end{array}$ \\
\hline PPI use & $\begin{array}{l}\text { Education and auditing by pharmacy to } \\
\text { ensure appropriate use }\end{array}$ \\
\hline Prolonged LOS & $\begin{array}{l}\text { Early identification of patients safe to } \\
\text { discharge }\end{array}$ \\
\hline
\end{tabular}

See Muto [17], Dellit [25], and Zilberberg [44]

CDI C. difficile infection, ASP Antimicrobial Stewardship Program, $P P I$ proton pump inhibitor, LOS length of stay

\section{Antibiotics}

Antibiotics were first noted to be a risk factor for the development of CDI in the 1970s when it was observed that hamsters developed fatal colitis after exposure to clindamycin [9]. Antibiotic exposure is observed as a risk factor for CDI in 80-99\% of cases, but it should be noted that in cases of community-associated CDI, antibiotic exposure is frequently not encountered [27, 28]. The majority of antibiotics have been associated with CDI, most notably, fluoroquinolones, second and third generation cephalosporins, clindamycin, ampicillin, and amoxicillin $[17,27]$. Fluoroquinolones and second and third generation cephalosporins are often the most frequently prescribed antibiotics hospital wide and have caused facility-wide clonal outbreaks associated with high mortality rates [17, 29]. During outbreak situations, infection control measures alone are not enough, and it often requires restriction of the implicated antibiotics through an antimicrobial stewardship program (ASP) or other means to control an outbreak. This was demonstrated by two studies that showed a 56 and $60 \%$ reduction in incidence of CDI after targeting a decrease in the use of fluoroquinolones, cephalosporins, and clindamycin [17, 30, 31]. ASPs also effectively reduce CDI in non-outbreak setting [32, 33].

Studies indicate that more than half of hospitalized patients at any point in time are receiving antimicrobial therapy. Unfortunately, some studies suggest that up to $30 \%$ are prescribed inappropriately $[34,35]$ (Table 2). Given that the pathogenesis of CDI primarily relies on the disruption of the colonic bacterial flora by antibiotics, the misuse of antibiotics in hospitalized patients has a direct influence on CDI; therefore, hospital-based physicians in conjunction with ASPs can have a direct impact on CDI acquisition by curbing the misuse of antibiotics.

\section{Healthcare Exposure and Length of Stay}

Exposure to acute care hospitals and long-term care facilities are a common risk factor for CDI. Reports as early as the 1980 s indicate that up to $21 \%$ of previously uncolonized patients acquire $C$. difficile during an acute care hospitalization and inpatient colonization rates are as high as $15 \%[12,36]$. Increased acquisition occurs in hospital floors/settings with high $C$. difficile colonization pressure, a measurement of the proportion of patients colonized or infected with $C$. difficile within a defined hospital region (e.g., floor, ICU) during a specific time period [37]. 
Table 2 Reasons for inappropriate antibiotic use

\begin{tabular}{ll}
\hline $\begin{array}{l}\text { Reasons for unnecessary days of antibiotic } \\
\text { therapy }\end{array}$ & $\begin{array}{l}\text { No (\%) of unnecessary } \\
\text { days }\end{array}$ \\
\hline $\begin{array}{l}\text { Duration of therapy longer than necessary } \\
\text { Treatment of a non-infectious sequelae }\end{array}$ & $192(33)$ \\
$\begin{array}{l}\text { Treatment of colonization or } \\
\text { contamination }\end{array}$ & $94(16)$ \\
$\begin{array}{l}\text { Redundant coverage } \\
\text { Spectrum of activity not indicated }\end{array}$ & $60(10)$ \\
Adjustments not made in a timely manner & $20(3)$ \\
\hline
\end{tabular}

See Hecker [35]

Hospital studies have shown that in rooms with asymptomatic colonizers, spores can be recovered in $29 \%$ of cases, in $50 \%$ of symptomatic cases, and in greater than $90 \%$ of rooms with incontinent CDI patients [36, 38]. Spores are highly resistant to alcohol gel products and many commonly used environmental disinfectants. Accordingly, longer lengths of stay have been implicated in both the acute and long-term care setting as a risk factor for $\mathrm{CDI}$ and CDI recurrence, as exposure time to $C$. difficile spores increases [28].

Infection control programs are of the utmost importance to enforce early and correct isolation precautions (gowns, gloves, and hand washing rather than alcohol gel) for CDI patients and to recognize potential outbreaks. These efforts lead to reduced $C$. difficile pressure and decreased exposure. Length of isolation precautions vary; some institutions, particularly during an outbreak, favor isolation for an affected patient during the entire hospitalization, whereas other programs stop isolation when patients are no longer having diarrhea. However, patients clinically cured of CDI after treatment, still have skin and environmental $C$. difficile contamination of 58 and $50 \%$, respectively [39]. Environmental efforts to reduce contamination should include frequent and terminal cleaning with chlorine-based sporicides such as $10 \%$ bleach [40••]. Hydrogen peroxide solutions, UV light and copper-based surfaces show promise, but should only be used adjunctively with chlorine-based sporicides [40••, 41-43].

\section{Age}

During the past decade, age $>65$ years old has been consistently found across multiple studies to be associated with increased rates of infection and more severe disease [18, $44,45]$. The reasons for this are likely due to a higher number of comorbidities, a dysregulated inflammatory state associated with aging, a depressed humoral response to antigenic stimuli, and a loss of intestinal barrier defenses, protective cellular signaling, as well as impaired reparative mechanisms. A lack of a systemic immunoglobulin $\mathrm{G}$ ( $\mathrm{IgG}$ ) response to $\mathrm{CDI}$ has been implicated as both a risk for disease recurrence and an increased 30-day mortality [46, 47]. Animal studies have shown an increased inflammatory cytokine response in aged mice as compared to young mice in response to $\mathrm{CDI}$, associated with greater symptomatology [48]. Recognition that age is a risk factor for disease should guide the hospital-based physician not only in suspicion and early management but also to take measures to avoid unnecessary antibiotics in this vulnerable population.

\section{Acid-Reducing Medications}

Fifty percent of inpatients prescribed proton pump inhibitors (PPI) are done so inappropriately [49]. In 2012, the Food and Drug Administration (FD) issued a warning that stomach acid-reducing medications may be associated with an increased risk of CDI, with higher doses conferring a greater risk. This decision was based on twenty-three of twenty-eight studies that found a 1.4-2.8-fold increased risk of CDI with PPI exposure [50]. Additionally, histamine blockers have also been implicated though to a lesser extent. Not all studies, though, have found an associated risk of CDI with PPI use, so this data is somewhat controversial. However, targeted efforts to identify patients inappropriately prescribed acid-reducing medications should be undertaken to help decrease CDI incidence.

\section{Diagnosis}

There are several CDI diagnostic laboratory tests with wide ranges of both sensitivity and specificity available within the hospital setting (Table 3 [51-55]). Also, the presence of pseudomembranes on endoscopy is pathognomonic for CDI. In severe cases or in cases with a high clinical suspicion, it is imperative to initiate therapy and place on isolation precautions early even prior to establishing a laboratory diagnosis. Guidelines recommend testing only in patients that have three or greater loose watery stools within a 24-h period. Formed stools should not be tested as this is not clinically consistent with CDI and is a source of undue costs.

Toxin enzyme immunoassays (EIA) test for the presence of both toxins $\mathrm{A}$ and $\mathrm{B}$ and were frequently the only available diagnostic test in the hospital setting. Sensitivity and specificity in comparison to gold standard cytotoxin neutralization assays are 58 and $95 \%$ with a positive (PPV) and negative predictive value (NPV) of 70 and $92 \%$ [54]. Newer antigen kits testing for the presence of 
Table 3 Common $C$. difficile diagnostic tests available in the hospital setting

\begin{tabular}{|c|c|c|c|c|}
\hline Test & $\begin{array}{l}\text { Sensitivity } \\
(\%)\end{array}$ & $\begin{array}{l}\text { Specificity } \\
(\%)\end{array}$ & Advantage & Disadvantage \\
\hline Toxin A/B EIA & 58 & 95 & Cheap & $\begin{array}{l}\text { Low NPV-High number of } \\
\text { false negative tests }\end{array}$ \\
\hline GDH antigen & $>90$ & $80-100$ & High NPV-good screening tool & $\begin{array}{l}\text { Low PPV-High number of } \\
\text { false positive tests }\end{array}$ \\
\hline $\begin{array}{l}\text { 2-Step algorithm: GDH +PCR (Can also be } \\
\text { combined with EIA) }\end{array}$ & 94 & 99 & $\begin{array}{l}\text { Cheaper than screening all stools } \\
\text { with PCR }\end{array}$ & Time intensive \\
\hline Toxin B PCR & $90-100$ & $94-97$ & $\begin{array}{l}\text { Rapid turnaround time. Option to } \\
\text { test for the BI strain }\end{array}$ & Expensive \\
\hline
\end{tabular}

See Goldenberg [51, 52], Huang [53], Novak-Weekley [54], Shetty [55]

$E I A$ enzyme linked immunoassay, $N P V$ negative predictive value, $G D H$ glutamate dehydrogenase, $P P V$ positive predictive value, $P C R$ polymerase chain reaction

glutamate dehydrogenase $(\mathrm{GDH})$, an antigen present in both toxigenic and non-toxigenic $C$. difficile, are now available. Its NPV is $>99 \%$ with a PPV of $50 \%$ making it a useful screening test [56]. A two-step algorithm, utilizing a screening GDH test combined with a polymerase chain reaction (PCR) test for the presence of the tcdB gene (transcribes toxin B) has a sensitivity and specificity of 94 and $99 \%$, respectively [51]. Because of their high sensitivity and specificity (94-100 and 96-97\%, respectively) and ability to test for the BI strain, many facilities are utilizing tcdB PCR without screening tests [52, 54]. The downside to the use of PCR only without the two-step algorithm is that it's expensive, but the benefit is that there is decreased testing time as compared to the two-step algorithm.

Early recognition of disease and diagnostic testing is essential for accurate epidemiologic surveillance. A standardized case definition, based on the timing of infection in relation to healthcare exposure (hospital, long-term acute care hospital, rehabilitation center) is now recommended by the Society for Healthcare Epidemiology or America/ Infectious Disease Society of America (SHEA/IDSA) as follows $[40 \bullet \bullet]$ :

1. Healthcare facility (HCF)-onset, $\mathrm{HCF}$-associated CDI: Onset and diagnosis after $48 \mathrm{~h}$ of inpatient facility hospital admission and prior to discharge.

2. Community-onset, HCF-associated CDI: Onset and diagnosis within 4 weeks after inpatient facility discharge.

3. Community-associated CDI: Onset and diagnosis 12 weeks after inpatient facility discharge.

4. Indeterminate: Onset between 4-12 weeks after facility discharge.

Understanding these acquisition trends can help identify hospital-wide outbreaks and are crucial to hospitals since financial reimbursement for hospital-acquired infections will diminish and hospital onset CDI rates will be made public.

\section{Disease Presentation and Definition}

Symptoms of CDI range from mild, watery to profuse diarrhea, leading to profound dehydration and shock. Presentation typically occurs days to weeks after antibiotic exposure, but as previously stated, can occur with no antibiotic or healthcare exposure and at time months after antibiotic exposure. When patients present with symptoms of abdominal distention, abdominal pain, and lack of bowel movements, it indicates a more severe case. Disease severity is generally graded as mild to moderate, severe, and severe with complications. Various definitions of disease severity exist, with some including a combination of physical symptoms and lab work. SHEA/IDSA defines disease as follows [40••]:

\section{Mild to Moderate Disease}

1. White blood cell (WBC) less than 15,000 cells/uL

2. Cr of less than 1.5 -fold the premorbid state.

Severe disease

1. WBC greater than 15,000 cells/uL

2. Cr of greater than 1.5 -fold the premorbid state

Severe disease with complications

1. Presence of severe disease

2. Ileus

3. Toxic megacolon

4. Shock

Additional indicators of disease severity include a comorbid state, immunosuppression, bandemia, the use of 
vasopressor therapy, hypoalbuminemia, and an elevated lactate level [27, 57•, 58]. Early recognition of severe disease and a fulminant state is of the utmost importance in order to start antibiotics and involve surgical colleagues when colectomy is deemed necessary (see Treatment: Fulminant Disease section below).

\section{Treatment}

CDI treatment varies depending on the severity of illness, which is defined above. In 2008, SHEA/IDSA published evidence-based recommendations for the treatment of CDI based on severity of the illness and/or recurrence (Table 4). Newer agents, associated with higher cure rate, less recurrence, and less microbiota disturbance are now available or in trial.

\section{Mild to Moderate Disease}

Metronidazole $(500 \mathrm{mg}$ orally three times a day for 10 days) is still recommended for a first presentation of mild to moderate disease according to the SHEA/IDSA guidelines. Evidence to support this comes from a small study performed prior to the prevalence of the BI strain and demonstrated that treatment with metronidazole or oral vancomycin for 10 days led to clinical cure in 90 and $98 \%$ of patients, respectively ( $p=.36$ ) [59]. Recurrence rates of $15 \%$ were seen in both groups. Since then, a larger scale study demonstrated cure rates for metronidazole and vancomycin of 75 and $82 \%$, respectively [60•]. The lower cure rate in the latter study is thought to be due to the presence of the BI strain whereas the first study was undertaken prior to the widespread distribution of the strain. Though this newer study did not reach statistical significance, the trends in improved outcomes in this and other studies have led some to suggest vancomycin over metronidazole even in mild to moderate cases [61].

\section{Severe Disease}

Vancomycin (125 mg orally four times a day for ten to 14 days) is recommended for severe disease. It was previously shown to lead to clinical cure in $97 \%$ of cases as compared to $76 \%$ given metronidazole $(p=0.02)$ [59]. Better cure rates were also seen in a larger scale study with vancomycin being more effective than metronidazole for clinical cure (78.5 vs $66.3 \%, p=.059$ ) [60•]. Similarly, the difference in clinical cure between the two studies has been hypothesized to be due to the presence of the BI strain in the latter study.

\section{Severe Disease with Complications}

High dose vancomycin dosed $500 \mathrm{mg}$ orally four times a day by mouth or nasogastric tube combined with metronidazole $500 \mathrm{mg}$ intravenously three times per day is recommended for severe disease with complications such as ileus, toxic megacolon, or shock [40••]. Intravenous metronidazole is utilized as it is secreted into the bowel even in the presence of an ileus. If an ileus is present, then $500 \mathrm{mg}$ of vancomycin in $125 \mathrm{ml}$ of normal saline by retention enema every $6 \mathrm{~h}$, rather than orally, is recommended in addition to the metronidazole. If clinical conditions worsen, surgical intervention is needed.

\section{Fulminant Disease}

Even despite antimicrobial treatment, CDI can progress to fulminant disease in $9 \%$ of cases [17]. Signs of progressive disease include increasing number of bowel movements, increasing white blood cell count, worsening abdominal distension, more pronounced shock, and increasing lactate levels. Recognizing these signs and the urgent need for surgical intervention is of great importance as increased time to surgery is associated with a higher mortality $[57 \cdot, 62,63]$. Mortality in fulminant cases can be as high as $60 \%$ in those treated medically and $50 \%$ in those undergoing total or subtotal colectomy [58]. Admission of fulminant patients to a Medicine as opposed to a Surgical service is associated with an increased mortality risk, thought to be due to an increased time to surgery [57•]. Other predictors of mortality in fulminant cases include $\mathrm{WBC}>50,000$ cells/uL ( $87 \%$ mortality), vasopressor use (66\% mortality), immunosuppression (73\% mortality), and/or a lactate $>5 \mathrm{mmol} / \mathrm{L}$ ( $93 \%$ mortality), even if a colectomy is undertaken, whereas a colectomy in patients with WBC of greater than 20,000 cells/uL, age greater than 65 , immunocompetent state, and lactate between 2.2 and $4.9 \mathrm{mmol} / \mathrm{L}$ are associated with a mortality benefit $[57 \cdot, 58]$ (Table $5[57 \bullet, 58,64]$ ). The use of a loop ileostomy with colonic lavage and direct infusion of vancomycin into the colon has shown promise, dropping one center's mortality in fulminant cases from $50 \%$ in those undergoing colectomy to $19 \%$ in those with a loop ileostomy $(p=0.006)$ [65]; the use of loop ileostomy additionally decreases morbidity associated with colectomy with end ileostomy.

\section{Recurrent Disease}

CDI recurs in $25-30 \%$ of patients, with the BI strain associated with a greater recurrence risk. A lack of an $\operatorname{IgG}$ 
Table 4 Treatment strategies based on severity of CDI

\begin{tabular}{|c|c|c|}
\hline $\begin{array}{l}\text { Disease } \\
\text { severity }\end{array}$ & $\begin{array}{l}\text { Clinical and laboratory } \\
\text { data }\end{array}$ & Treatment \\
\hline $\begin{array}{l}\text { 1st Episode- } \\
\mathrm{mild} / \mathrm{mod}\end{array}$ & $\begin{array}{l}\text { WBC }<15,000 \text { cells } / u L \\
\mathrm{Cr}<1.5 \text { times } \\
\text { premorbid state }\end{array}$ & $\begin{array}{l}\text { Metronidazole } 500 \mathrm{mg} \\
\text { PO TID } \times 10 \mathrm{~d}\end{array}$ \\
\hline $\begin{array}{l}\text { 1st Episode- } \\
\text { severe }\end{array}$ & $\begin{array}{l}\text { WBC }>15,000 \text { cells/uL, } \\
\mathrm{Cr}>1.5 \text { times } \\
\text { premorbid state, } \\
\text { Consider if }>65 \text { years }\end{array}$ & $\begin{array}{l}\text { Vancomycin } 125 \mathrm{mg} \text { PO } \\
\text { QID } \times 10-14 \mathrm{~d}\end{array}$ \\
\hline $\begin{array}{l}\text { Severe, } \\
\text { complicated }\end{array}$ & $\begin{array}{l}\text { Hypotension, shock, } \\
\text { ICU, megacolon, ileus }\end{array}$ & $\begin{array}{l}\text { Vancomycin } 500 \mathrm{mg} \text { PO } \\
\text { QID + Metronidazole } \\
500 \mathrm{mg} \text { IV TID. } \\
\text { Vancomycin retention } \\
\text { enema QID (500 mg } \\
\text { mixed in } 125 \mathrm{ml} \text { of } \\
\text { normal saline) with } \\
\text { ileus } \\
\text { Early involvement of } \\
\text { Surgery }\end{array}$ \\
\hline $\begin{array}{l}\text { 1st } \\
\text { Recurrence }\end{array}$ & & Same as initial treatment \\
\hline $\begin{array}{l}\text { 2nd } \\
\text { Recurrence }\end{array}$ & & $\begin{array}{l}\text { Vancomycin taper with } \\
\text { pulse }^{\mathrm{a}}\end{array}$ \\
\hline
\end{tabular}

See Cohen $\left[40^{\bullet \bullet}\right]$

CDI C. difficile infection, $W B C$ white blood cell count

${ }^{a}$ Vancomycin $125 \mathrm{mg}$ PO $4 \mathrm{x} /$ day $\times 14 \mathrm{~d}$, then $125 \mathrm{mg} P O$ TID $\times 7 \mathrm{~d}$, then $125 \mathrm{mg}$ PO BID $\times 7 \mathrm{~d}$, then $125 \mathrm{mg}$ PO $\mathrm{q}$ day $\times 7 \mathrm{~d}$, then $125 \mathrm{mg}$ PO qod $\times 14 \mathrm{~d}$

response to infection and/or a continued drop of colonization resistance due to microbiota elimination with vancomycin and metronidazole is a possible reason for this recurrence [46]. SHEA/IDSA guidelines recommend for a first recurrence, a course identical to the first antibiotic course. With a second recurrence, a tapering course of vancomycin over several weeks is recommended (Table 4) $[40 \bullet \bullet$.

\section{New Treatments}

Fidaxomicin, a new macrocyclic antibiotic, dosed $200 \mathrm{mg}$ orally twice a day for 10 days, is associated with a lower recurrence rate as compared to vancomycin (15.4 vs. $25.3 \%, p=0.005)$ [24••]. Whereas vancomycin and fidaxomicin are equally effective in resolving CDI symptoms, fidaxomicin preserves the microbiota, likely leading to the decreased recurrence [66]. The lower recurrence trend is similar when treating a first recurrence as well (20\% fidaxomicin vs $36 \%$ vancomycin, $p=0.045$ ) [67]. Fidaxomicin's costs have led some practitioners and hospitals to restrict its use, but a recent analysis has shown that it may be a more cost-effective treatment as compared to vancomycin [68].
Table 5 Clinical and laboratory findings associated with mortality in fulminant CDI

Increased time to surgery

Admission to a medical rather than surgical service ${ }^{\mathrm{a}}$

Shock requiring vasopressor use

Immunosuppression

Age greater than 75 years

Lactate greater than $5 \mathrm{mmol} / \mathrm{L}$

Respiratory failure

WBC greater than $35,000-50,000$ cells/L or less than

$4,000 \times$ cells $/ \mathrm{L}$

Greater than $10 \%$ bandemia

Multi-organ failure

Mental status changes

See Sailhamer [57•], Lamontagne [58], Perera [64], Byrn [61]

a Associated with an increased length of time prior to surgery

The most effective treatment for CDI recurrence remains fecal microbiota transplant (FMT), in which stool from a healthy donor is "transplanted" into the patient, restoring colonization resistance. Prior to a randomized controlled trial showing a cure rate of $94 \%$ with FMT by nasoduodenal infusion, there were numerous case series and reports, as early as 1958, proving its benefit by colonoscopy and/or retention enema instillation, with cure rates ranging from 84 to $100 \%$ [69-71••, 72]. Self-administered FMT has even been proven effective [72]. The biggest barrier to its implementation is the FDA's lack of clear guidance as to the necessity of an investigational new drug (IND) application. In June 2013, the FDA said an IND is not necessary to utilize FMT, but there is still concern it may be needed in the future. Additional barriers to implementation include institutions unwilling to adopt its use, lack of reimbursement by insurance plans, high costs associated with screening donors and recipients, and a lack of doctors, nurses, and/or ancillary staff willing to participate. Cost analysis, however, has shown it to be the most cost-effective treatment for CDI recurrence making it difficult for these barriers to be justified [74].

Surotomycin, an anti-C. difficile lipopeptide, currently in Phase 3 trials, has shown comparable cure rates to vancomycin and improved recurrence rates (17 vs $36 \%$, $p<0.035$ ) [75]. Additional promising treatments include toxin A- and B-specific monoclonal antibodies, frozen fecal inocula for instillation, and stool substitute preparations of purified intestinal bacteria [76-78].

\section{Conclusion}

The turn of the century saw a surge in CDI prevalence and CDI-associated deaths. This has now plateaued as we further understand disease pathogenesis and epidemiology 
associated with the "epidemic" BI strain. Our understanding of the preservation of the intestinal microbiota for disease prevention is greater and major efforts are being undertaken by some hospitals to reduce inappropriate antimicrobial use in the hopes of reducing CDI incidence. Newer studies are showing a trend toward improved outcome with vancomycin as compared to metronidazole. New anti-C. difficile drugs have shown promise in reducing recurrence, but by far the most promising treatment remains FMT and restoration of a healthy intestinal microbiota. Emergency room and hospital-based physicians can be at the forefront of battling this disease by initiating appropriate management early, recognizing factors associated with disease acquisition, facilitating the acceptance of ASP and infection control programs, and advocating for the approval of FMT in the hospital setting.

\section{Compliance with Ethics Guidelines}

Conflict of Interest Sean W Pawlowski has no reported conflict of interest.

Human and Animal Rights and Informed Consent This article does not contain any studies with human or animal subjects performed by any of the authors.

\section{References}

Papers of particular interest, published recently, have been highlighted as:

- Of importance

•- Of major importance

1. Magill SS, Edwards JR, Bamberg W, Beldavs ZG, Dumyati G, Kainer MA, et al. Multistate point-prevalence survey of health careassociated infections. New Engl J Med. 2014;370(13):1198-208.

2. Redelings MD, Sorvillo F, Mascola L. Increase in Clostridium difficile-related mortality rates, United States, 1999-2004. Emerg Infect Dis. 2007;13(9):1417-9.

3. Price MF, Dao-Tran T, Garey KW, Graham G, Gentry LO, Dhungana L, et al. Epidemiology and incidence of Clostridium difficile-associated diarrhoea diagnosed upon admission to a university hospital. J Hosp Infect. 2007;65(1):42-6.

4. Lucado J, Gould C, Elixhauser A. Clostridium difficile infections (CDI) in Hospital Stays, 2009: Statistical Brief \#124. In: Rockville MD Healthcare Cost and Utilization Project (HCUP) statistical briefs. Washington: Agency for Health Care Policy and Research (US); 2006.

5. Centers for Disease, Control. Severe Clostridium difficile-Associated Disease in Populations Previously at Low Risk-Four States. Morbid Mortal Wkly Rep. 2005;4(47):1201-5.

6. - See I, Mu Y, Cohen J, Beldavs ZG, Winston LG, Dumyati G, et al. NAP1 strain type predicts outcomes from Clostridium difficile infection. Clin Infect Dis. 2014;58(10):1394-400. Definitive publication identifying the "epidemic" BI strain as a cause of increased mortality and severe disease, as compared to non "epidemic" strains.
7. McDonald LC, Killgore GE, Thompson A, Owens RC Jr, Kazakova $\mathrm{SV}$, Sambol SP, et al. An epidemic, toxin gene-variant strain of Clostridium difficile. New Engl J Med. 2005;353(23):2433-41.

8. Hall ICOE. Intestinal flora in newborn infants with description of a new pathogenic anaerobe. Am J Dis Child. 1935;49:390-402.

9. Bartlett JG, Onderdonk AB, Cisneros RL, Kasper DL. Clindamycin-associated colitis due to a toxin-producing species of Clostridium in hamsters. J Infect Dis. 1977;136(5):701-5.

10. Noren T, Akerlund T, Back E, Sjoberg L, Persson I, Alriksson I, et al. Molecular epidemiology of hospital-associated and community-acquired Clostridium difficile infection in a Swedish county. J Clin Microbiol. 2004;42(8):3635-43.

11. Galdys AL, Nelson JS, Shutt KA, Schlackman JL, Pakstis DL, Pasculle AW, et al. Prevalence and Duration of Asymptomatic Clostridium difficile Carriage among Healthy Subjects in Pittsburgh Pennsylvania. J Clin Microbiol. 2014;52(7):2406-9.

12. Alasmari F, Seiler SM, Hink T, Burnham CA, Dubberke ER. Prevalence and Risk Factors for Asymptomatic Clostridium difficile Carriage. Clin Infect Dis. 2014;59(2):216-22.

13. Jank T, Giesemann T, Aktories K. Rho-glucosylating Clostridium difficile toxins $\mathrm{A}$ and $\mathrm{B}$ : new insights into structure and function. Glycobiology. 2007;17(4):15r-22r.

14. Warny M, Keates AC, Keates S, Castagliuolo I, Zacks JK, Aboudola S, et al. p38 MAP kinase activation by Clostridium difficile toxin A mediates monocyte necrosis, IL-8 production, and enteritis. J Clin Investig. 2000;105(8):1147-56.

15. Pepin J, Valiquette L, Alary ME, Villemure P, Pelletier A, Forget $\mathrm{K}$, et al. Clostridium difficile-associated diarrhea in a region of Quebec from 1991 to 2003: a changing pattern of disease severity. CMAJ. 2004;171(5):466-72.

16. Archibald LK, Banerjee SN, Jarvis WR. Secular trends in hospital-acquired Clostridium difficile disease in the United States, 1987-2001. J Infect Dis. 2004;189(9):1585-9.

17. Muto CA, Pokrywka M, Shutt K, Mendelsohn AB, Nouri K, Posey $\mathrm{K}$, et al. A large outbreak of Clostridium difficile-associated disease with an unexpected proportion of deaths and colectomies at a teaching hospital following increased fluoroquinolone use. Infect Control Hosp Epidemiol. 2005;26(3):273-80.

18. Zilberberg MD, Shorr AF, Kollef MH. Increase in adult Clostridium difficile-related hospitalizations and case-fatality rate, United States, 2000-2005. Emerg Infect Dis. 2008;14(6):929-31.

19. Dawson LF, Valiente E, Donahue EH, Birchenough G, Wren BW. Hypervirulent Clostridium difficile PCR-ribotypes exhibit resistance to widely used disinfectants. PLoS ONE. 2011;6(10):e25754.

20. Aronoff DM. Editorial commentary: host-pathogen interactions in Clostridium difficile infection: it takes two to tango. Clin Infect Dis. 2014;58(10):1401-3.

21. Lawley TD, Clare S, Walker AW, Stares MD, Connor TR, Raisen $\mathrm{C}$, et al. Targeted restoration of the intestinal microbiota with a simple, defined bacteriotherapy resolves relapsing Clostridium difficile disease in mice. PLoS Pathog. 2012;8(10):e1002995.

22. Warny M, Pepin J, Fang A, Killgore G, Thompson A, Brazier J, et al. Toxin production by an emerging strain of Clostridium difficile associated with outbreaks of severe disease in North America and Europe. Lancet. 2005;366(9491):1079-84.

23. Akerlund T, Persson I, Unemo M, Noren T, Svenungsson B, Wullt $\mathrm{M}$, et al. Increased sporulation rate of epidemic Clostridium difficile Type 027/NAP1. J Clin Microbiol. 2008;46(4):1530-3.

24. • Louie TJ, Miller MA, Mullane KM, Weiss K, Lentnek A, Golan Y, et al. Fidaxomicin versus vancomycin for Clostridium difficile infection. The New Engl J Med. 2011;364(5):422-31. Randomized controlled trial showing superior recurrence rates with fidaxomcin as compared to vancomcyin.

25. Dellit TH, Owens RC, McGowan JE Jr, Gerding DN, Weinstein RA, Burke JP, et al. Infectious Diseases Society of America and the Society for Healthcare Epidemiology of America guidelines 
for developing an institutional program to enhance antimicrobial stewardship. Clin Infect Dis. 2007;44(2):159-77.

26. Zilberberg MD, Reske K, Olsen M, Yan Y, Dubberke ER. Development and validation of a recurrent Clostridium difficile risk-prediction model. J Hosp. Med. 2014;9(7):418-23.

27. Kelly CP. Current strategies for management of initial Clostridium difficile infection. J Hosp Med. 2012;7(Suppl 3):S5-10.

28. Pawlowski SW LR. C.difficile infection presentation and recurrence risks in spinal cord and traumatic brain injury patients in an inpatient rehabilitation hospital. Abstract \#1399. ID Week annual meeting. San Francisco, CA; 2013.

29. Loo VG, Poirier L, Miller MA, Oughton M, Libman MD, Michaud $\mathrm{S}$, et al. A predominantly clonal multi-institutional outbreak of Clostridium difficile-associated diarrhea with high morbidity and mortality. New Engl J Med. 2005;353(23): 2442-9.

30. Valiquette L, Cossette B, Garant MP, Diab H, Pepin J. Impact of a reduction in the use of high-risk antibiotics on the course of an epidemic of Clostridium difficile-associated disease caused by the hypervirulent NAP1/027 strain. Clin Infect Dis. 2007;45(Suppl 2):S112-21.

31. Climo MW, Israel DS, Wong ES, Williams D, Coudron P, Markowitz SM. Hospital-wide restriction of clindamycin: effect on the incidence of Clostridium difficile-associated diarrhea and cost. Ann Intern Med. 1998;128(12 Pt 1):989-95.

32. Wenisch JM, Equiluz-Bruck S, Fudel M, Reiter I, Schmid A, Singer E, et al. Decreasing Clostridium difficile infections by an antimicrobial stewardship program reducing moxifloxacin use. Antimicrob Agents Chemother. 2014;58(9):5079-83.

33. Price J, Cheek E, Lippett S, Cubbon M, Gerding DN, Sambol SP, et al. Impact of an intervention to control Clostridium difficile infection on hospital- and community-onset disease; an interrupted time series analysis. Clin Microbiol Infect. 2010;16(8):1297-302.

34. Centers for Disease Control. Vital signs: improving antibiotic use among hospitalized patients. Morbid Mortal Wkly Rep. 2014;63(9):7.

35. Hecker MT, Aron DC, Patel NP, Lehmann MK, Donskey CJ. Unnecessary use of antimicrobials in hospitalized patients: current patterns of misuse with an emphasis on the antianaerobic spectrum of activity. Arch Intern Med. 2003;163(8):972-8.

36. McFarland LV, Mulligan ME, Kwok RY, Stamm WE. Nosocomial acquisition of Clostridium difficile infection. New Engl J Med. 1989;320(4):204-10.

37. Dubberke ER, Reske KA, Olsen MA, McMullen KM, Mayfield $\mathrm{JL}$, McDonald LC, et al. Evaluation of Clostridium difficileassociated disease pressure as a risk factor for $\mathrm{C}$ difficile-associated disease. Arch Intern Med. 2007;167(10):1092-7.

38. Samore MH, Venkataraman L, DeGirolami PC, Arbeit RD, Karchmer AW. Clinical and molecular epidemiology of sporadic and clustered cases of nosocomial Clostridium difficile diarrhea. Am J Med. 1996;100(1):32-40.

39. Sethi AK, Al-Nassir WN, Nerandzic MM, Bobulsky GS, Donskey CJ. Persistence of skin contamination and environmental shedding of Clostridium difficile during and after treatment of C. difficile infection. Infection control and hospital epidemiology. Off J Soc Hosp Epidemiol Am. 2010;31(1):21-7.

40. • Cohen SH, Gerding DN, Johnson S, Kelly CP, Loo VG, McDonald LC, et al. Clinical practice guidelines for Clostridium difficile infection in adults: 2010 update by the society for healthcare epidemiology of America (SHEA) and the infectious diseases society of America (IDSA). Infect Control Hosp Epidemiol. 2010;31(5):431-55. Updated evidence based guidelines for the treatment, prevention, and monitoring of C.difficile infection.

41. Best EL, Parnell P, Thirkell G, Verity P, Copland M, Else P, et al. Effectiveness of deep cleaning followed by hydrogen peroxide decontamination during high Clostridium difficile infection incidence. J Hosp Infect. 2014;87(1):25-33.

42. Nerandzic MM, Donskey CJ. Triggering germination represents a novel strategy to enhance killing of Clostridium difficile spores. PLoS ONE. 2010;5(8):e12285.

43. Weaver L, Michels HT, Keevil CW. Survival of Clostridium difficile on copper and steel: futuristic options for hospital hygiene. J Hosp Infect. 2008;68(2):145-51.

44. Zilberberg MD, Reske K, Olsen M, Yan Y, Dubberke ER. Risk factors for recurrent Clostridium difficile infection (CDI) hospitalization among hospitalized patients with an initial CDI episode: a retrospective cohort study. BMC Infect Dis. 2014;14(1):306.

45. Abou Chakra CN. Pepin J, Sirard S, Valiquette L. Risk Factors for Recurrence, Complications and Mortality in Clostridium difficile Infection: a Systematic Review. PLoS ONE. 2014;9(6):e98400.

46. Kyne L, Warny M, Qamar A, Kelly CP. Association between antibody response to toxin $\mathrm{A}$ and protection against recurrent Clostridium difficile diarrhoea. Lancet. 2001;357(9251):189-93.

47. Solomon K, Martin AJ, O’Donoghue C, Chen X, Fenelon L, Fanning S, et al. Mortality in patients with Clostridium difficile infection correlates with host pro-inflammatory and humoral immune responses. J Med Microbiol. 2013;62(Pt 9):1453-60.

48. Pawlowski SW KG, Calabrese G, Freire R, Platts-Mills James, AlcantaraWarren C, Guerrant RL. Aging predisposes mice to acute symptomatic disease and prolonged weight loss in a murine model of Clostridium difficile infection. Abstract \#915, ID Week annual meeting. Philadelphia, PA; 2011.

49. Reid M, Keniston A, Heller JC, Miller M, Medvedev S, Albert RK. Inappropriate prescribing of proton pump inhibitors in hospitalized patients. J Hosp Med. 2012;7(5):421-5.

50. FDA drug safety communication:Clostridium difficile associated diarrhea can be associated with stomach acid drugs known as proton pump inhibitors. www.fda.gov/drugs/drugsafety/ucm290510.htm. Accessed July 5, 2014.

51. Goldenberg SD, Cliff PR, Smith S, Milner M, French GL. Twostep glutamate dehydrogenase antigen real-time polymerase chain reaction assay for detection of toxigenic Clostridium difficile. J Hosp Infect. 2010;74(1):48-54.

52. Goldenberg SD, Dieringer T, French GL. Detection of toxigenic Clostridium difficile in diarrheal stools by rapid real-time polymerase chain reaction. Diagn Microbiol Infect Dis. 2010;67(3):304-7.

53. Huang H, Weintraub A, Fang H, Nord CE. Comparison of a commercial multiplex real-time PCR to the cell cytotoxicity neutralization assay for diagnosis of clostridium difficile infections. J Clin Microbiol. 2009;47(11):3729-31.

54. Novak-Weekley SM, Marlowe EM, Miller JM, Cumpio J, Nomura JH, Vance PH, et al. Clostridium difficile testing in the clinical laboratory by use of multiple testing algorithms. J Clin Microbiol. 2010;48(3):889-93.

55. Shetty N, Wren MW, Coen PG. The role of glutamate dehydrogenase for the detection of Clostridium difficile in faecal samples: a meta-analysis. J Hosp Infect. 2011;77(1):1-6.

56. Gilligan PH. Is a two-step glutamate dehyrogenase antigencytotoxicity neutralization assay algorithm superior to the premier toxin A and B enzyme immunoassay for laboratory detection of Clostridium difficile? J Clin Microbiol. 2008;46(4):1523-5.

57. - Sailhamer EA, Carson K, Chang Y, Zacharias N, Spaniolas K, Tabbara M, et al. Fulminant Clostridium difficile colitis: patterns of care and predictors of mortality. Arch Surg (Chicago, Ill: 1960). 2009;144(5):433-9; discussion 9-40. Informative publication on the risk factors associated with mortality in fulminant CDI with or without colectomy.

58. Lamontagne F, Labbe AC, Haeck O, Lesur O, Lalancette M, Patino $\mathrm{C}$, et al. Impact of emergency colectomy on survival of 
patients with fulminant Clostridium difficile colitis during an epidemic caused by a hypervirulent strain. Ann Surg. 2007;245(2):267-72.

59. Zar FA, Bakkanagari SR, Moorthi KM, Davis MB. A comparison of vancomycin and metronidazole for the treatment of Clostridium difficile-associated diarrhea, stratified by disease severity. Clin Infect Dis. 2007;45(3):302-7.

60. - Johnson S, Louie TJ, Gerding DN, Cornely OA, Chasan-Taber S, Fitts D, et al. Vancomycin, Metronidazole, or Tolevamer for Clostridium difficile Infection: results from two multinational, randomized, controlled trials. Clin Infect Dis. 2014;59(3):345-54. A subgroup analysis showing improved outcomes in patient administered vancomcyin as opposed to metronidazole for CDI treatment.

61. Wilcox WH. Editorial commentary: the trials and tribulations of treating clostridium difficile infection-one step backward, one step forward, but still progress. Clin Infect Dis. 2014;59(3):355-7.

62. Byrn JC, Maun DC, Gingold DS, Baril DT, Ozao JJ, Divino CM. Predictors of mortality after colectomy for fulminant Clostridium difficile colitis. Arch Surg. 2008;143(2):150-4; discussion 5.

63. Halabi WJ, Nguyen VQ, Carmichael JC, Pigazzi A, Stamos MJ, Mills S. Clostridium difficile colitis in the United States: a decade of trends, outcomes, risk factors for colectomy, and mortality after colectomy. J Am Coll Surg. 2013;217(5):802-12.

64. Perera AD, Akbari RP, Cowher MS, Read TE, McCormick JT, Medich DS, et al. Colectomy for fulminant Clostridium difficile colitis: predictors of mortality. Am Surg. 2010;76(4):418-21.

65. Neal MD, Alverdy JC, Hall DE, Simmons RL, Zuckerbraun BS. Diverting loop ileostomy and colonic lavage: an alternative to total abdominal colectomy for the treatment of severe, complicated Clostridium difficile associated disease. Ann Surg. 2011;254(3):423-7; discussion 7-9.

66. Louie TJ, Cannon K, Byrne B, Emery J, Ward L, Eyben M, et al. Fidaxomicin preserves the intestinal microbiome during and after treatment of Clostridium difficile infection (CDI) and reduces both toxin reexpression and recurrence of CDI. Clin Infect Dis. 2012;55(Suppl 2):S132-42.

67. Cornely OA, Miller MA, Louie TJ, Crook DW, Gorbach SL. Treatment of first recurrence of Clostridium difficile infection: fidaxomicin versus vancomycin. Clin Infect Dis. 2012;55(Suppl 2):S154-61.

68. Stranges PM, Hutton DW, Collins CD. Cost-effectiveness analysis evaluating fidaxomicin versus oral vancomycin for the treatment of Clostridium difficile infection in the United States. Value Health. 2013;16(2):297-304.

69. Lund-Tonnesen S, Berstad A, Schreiner A, Midtvedt T. Clostridium difficile-associated diarrhea treated with homologous feces. Tidsskrift for den Norske laegeforening : tidsskrift for praktisk medicin, ny raekke. 1998;118(7):1027-30.

70. Rohlke F, Surawicz CM, Stollman N. Fecal flora reconstitution for recurrent Clostridium difficile infection: results and methodology. J Clin Gastroenterol. 2010;44(8):567-70.

71. • van Nood E, Vrieze A, Nieuwdorp M, Fuentes S, Zoetendal EG, de Vos WM, et al. Duodenal infusion of donor feces for recurrent Clostridium difficile. New Engl J Med. 2013;368(5):407-15. The first randomized trial comparing fecal microbiota transplant (FMT) versus vancomycin therapy in the treatment of recurrent CDI, with results indiczting far superior outcomes with FMT.

72. Eiseman B, Silen W, Bascom GS, Kauvar AJ. Fecal enema as an adjunct in the treatment of pseudomembranous enterocolitis. Surgery. 1958;44(5):854-9.

73. Silverman MS, Davis I, Pillai DR. Success of self-administered home fecal transplantation for chronic Clostridium difficile infection. Clin Gastroenterol Hepatol. 2010;8(5):471-3.

74. Konijeti GG, Sauk J, Shrime MG, Gupta M, Ananthakrishnan AN. Cost-effectiveness of competing strategies for management of recurrent Clostridium difficile infection: a decision analysis. Clin Infect Dis. 2014;58(11):1507-14.

75. Surotomycin Fact Sheet. Cubist Pharmaceuticals. www.cubist. com/products/cdad. Accessed July 2, 2014.

76. Lowy I, Molrine DC, Leav BA, Blair BM, Baxter R, Gerding DN, et al. Treatment with monoclonal antibodies against Clostridium difficile toxins. New Engl J Med. 2010;362(3):197-205.

77. Youngster I, Sauk J, Pindar C, Wilson RG, Kaplan JL, Smith MB, et al. Fecal microbiota transplant for relapsing Clostridium difficile infection using a frozen inoculum from unrelated donors: a randomized, open-label, controlled pilot study. Clin Infect Dis. 2014;58(11):1515-22.

78. Petrof EO, Gloor GB, Vanner SJ, Weese SJ, Carter D, Daigneault $\mathrm{MC}$, et al. Stool substitute transplant therapy for the eradication of Clostridium difficile infection: 'RePOOPulating' the gut. Microbiome. 2013;1(1):3. 